\title{
KSP Inhibitor AZD4877
}

National Cancer Institute

\section{Source}

National Cancer Institute. KSP Inhibitor AZD4877. NCI Thesaurus. Code C64522.

A synthetic kinesin spindle protein (KSP) inhibitor with potential antineoplastic activity. AZD4877 selectively inhibits microtubule motor protein KSP (also called kinesin-5 or Eg5), which is essential for the formation of bipolar spindles and the proper segregation of sister chromatids during mitosis. Inhibition of KSP results in an inhibition of mitotic spindle assembly, activation of the spindle assembly checkpoint, induction of cell cycle arrest during the mitotic phase, thereby causing cell death in tumor cells that are actively dividing. Because KSP is not involved in postmitotic processes, such as neuronal transport, AZD4877 may be less likely to cause the peripheral neuropathy often associated with the tubulin-targeting agents. 